\title{
RISK ASSESSMENT OF SAND DUNE DISASTER IN RELATION TO GEOMORPHIC PROPERTIES AND VULNERABILITY IN THE SADUQ-YAZD ERG
}

\author{
JAMALI, A. A. ${ }^{*}-$ ZAREKIA, S. ${ }^{2}-$ RANDHIR, T. O. ${ }^{3}$ \\ ${ }^{I}$ Department of GIS-RS and Watershed Management, Maybod Branch, Islamic Azad University \\ Maybod, Iran \\ (e-mail: jamaliaa@maybodiau.ac.ir) \\ ${ }^{2}$ Rangeland and Forest Research Division, Yazd Agricultural and Natural Resources Research \\ and Education Center, AREEO \\ Yazd, Iran \\ (e-mail:s.zarekia@areeo.ac.ir) \\ ${ }^{3}$ Department of Environmental Conservation, University of Massachusetts \\ Amherst, MA 01003, USA \\ (e-mail: randhir@eco.umass.edu) \\ *Corresponding author \\ (Received $4^{\text {th }}$ Jul 2017; accepted $6^{\text {th }}$ Dec 2017)
}

\begin{abstract}
Sand dunes occupy a vast expanse of desert area in Iran and they are considered as a threat for urban areas and agricultural lands. Erg is an area of desert covered with shifting sand dunes. Saduq (Ashkezar) city, located in the west and northwest of the Yazd City, Iran, is surrounded by these mobile sand dunes. The aim of this study was the risk assessment of sand dune disaster in relation to geomorphic properties and vulnerability. The methods of satellite imageries, multi-layer perceptron (MLP) neural network, and geographic information system (GIS) were used. Sand dunes changes were mapped, and field surveys were carried out to resolve any ambiguities. The results show that the sand dunes in the center of Erg have moved closer to the city and agricultural lands. The dunes displacement (movement) was dependence to size, cover and shape and direction of them. These analyses can help to city governor and mayor for preventing of dunes offense toward the city.
\end{abstract}

Keywords: neural network, sand dunes, satellite image, remote sensing, Yazd, Iran

\section{Introduction}

Aeolian dune geomorphology is a product of the processes of wind erosion and deposition on land surface (Xiao et al., 2015). Thus, the formation and development of these landforms depend on windblown sand movement (Wu, 2003). The windblown sand movement is affected by the landscape characteristics, including vegetation, mulch, topography, wind regime and other regional factors. Studies in the history of aeolian geomorphology have enhanced the knowledge of dune morphology, formation and development conditions, dynamic processes of formation and evolution, and regional differentiation and regularity (Lancaster, 1995; Li and Ni, 2000; Livingstone et al., 2007). Studies in traditional dune geomorphology tend to focus on the formation and evolution of dunes that are in regions unaffected by complex terrain (Pye and Tsoar, 1990; Tsoar and Blumberg, 2002); however, sand dune formation also occurs in complex terrain. This research focuses on using new methods and softwares for visualization the trend and drift of the Erg and dunes that can be a danger for settlers. Tavakkolifard et al. (2013) were determined the risk of sand transportation to residential 
areas around Kashan-Iran Erg using anemometry data analysis without geographic information system (GIS) and remote sensing. Sandy landforms are morphologically divided into sand seas (Ergs), isolated dunes, dune fields, sandy plains, and sheets. At several locations, sand encroachment causes hazards to farmlands, highways, population centers and other infrastructures. Remote sensing techniques could be used effectively to monitor sand dune movements by comparing the multi-temporal satellite images (Pye and Tsoar, 1990) in Saduq having Erg, dune fields, and sandy plains. Bars, mulch, vegetation cover, or complex topography can decelerate, accelerate, and otherwise control the direction of the wind or windblown sand flow, particularly on the leeward side of trees and bushes. These changes in windblown sand movement lead to different erosion and deposition near the complex terrain, forming a variety of sand dunes, including small dunes, single dunes and string dunes (Evans, 1962; Cooke and Warren, 1973; Tsoar, 1983; Elbelrhiti et al., 2005; Elbelrhiti, 2012). Past studies in this area have documented local changes in bedform type (Al-Masrahy and Mountney, 2013) and associated spatial variation in aeolian lithofacies distributions in champ dune fields (Breed and Grow, 1979; Sweet et al., 1988; Kocurek and Lancaster, 1999; Saqqa and Atallah, 2004; Baas, 2007; Bullard et al., 2011). However, relatively few researchers have endeavored to measurably substantiate the form of spatial variability of the dune and interdune morphology from the center of aeolian dune-field systems to their borders (Jamali and Abdolkhani, 2009; Kocurek and Ewing, 2005; Wilkins and Ford, 2007; Ewing and Kocurek, 2010a; Kocurek et al., 2010; Hugenholtz and Barchyn, 2010). In modeling desert sites, Mili (2016) studied sites where the desert merges with wet coastal zones in Tunisia. Mili used GIS and modeling between water storages and some social factors in aquifer and floodplain sites merging of desert sites as important natural water storage and as natural protection against flooding. Meyer and Crews Meyer (2016) conducted a study to examine the suitability and fragmentation analysis in the Central Kalahari Game Reserve desert region, using GIS, remote sensing and GPS . the suitability analysis revealed three suggested corridors for protection Wildlife and Tourism. Potter (2016) has studied the analysis of desert sand dune migration patterns using Landsat image time series in the Southern California Desert. The predominant direction of sand dune movements was correctly mapped from the satellite imagery, as well as the migration distances of the leading edges of sand dunes over the entire 1992-2010 monitoring period. Some studies concentrated on extraction of sand dune encroachment by GIS (Dakhla Oases, the western desert of Egypt) (Ghadiry et al., 2012).

McCulloch and Pitts (1943) created a computational model for neural networks based on mathematics and algorithms called threshold logic. This model paved the way for neural network research to split into two distinct approaches. One approach focused on biological processes in the brain, and the other concentrated on the application of neural networks to artificial intelligence. In this study, some methods were composed to obtain sand dune movement. By using intelligence method such as multi-layer perceptron (MLP) and using a statistical method, we can find land changing and trend in Erg and we can control sand dune moving according to their movements.

The aim of this study is to model sand dune movement related to their shape properties (Dune's stoss and lee side, mulch, dune size) and vicinity threat in the SaduqYazd Erg. The specific objective is to evaluate effective factors in sand dune movement and its vulnerability using neural networks, statistical modeling and field surveys. Hypotheses are: (i) Sand dunes with different shapes are going to move, and change 
differently, and (ii) Erg movement towards the city depends on the wind direction and relative location of Erg.

\section{Materials and methods}

\section{Study area}

This survey was conducted on Yazd Erg dune groups in the center of Iran. The Erg sand dune lies near the Saduq (Ashkezar), and it is $20 \mathrm{~km}$ away from Yazd city. The area surrounded by some vulnerable land use such as road, farmland, and villages. The height of Yazd plain from the see level is $1200 \mathrm{~m}$ with the general slopes of less than $2 \%$.The plain is located in north of the Shirkouh Mountains (4040 m above sea level), which is the highest mountain range in central part of Iran. The Erg has been covered with flowing sands, its mean rainfall in the past thirty years was $61.7 \mathrm{~mm}$ the average annual temperature was $18.1^{\circ} \mathrm{C}$ and maximum, and minimum temperatures are $+46.5^{\circ} \mathrm{C}$ and $-15.5^{\circ} \mathrm{C}$, respectively. This area has a cold and dry climate, according to Emberger climate classification, and according to the Demarton classification, its climate is ultradry cold. The study area has some loose row and single vegetation cover such as Haloxylon sp. and Tamarix sp. (Baghestani et al., 2015; Figs. 1 and 2).

\section{Methods}

Following methods in literature (Tsoar, 1983; Tang et al., 2011), we studied the morphology of dune types (e.g. parabola and linear dunes) by using a variety of methods and measured parameters including slope, length, height and direction (Xiao et al., 2015). In the present study, the morphology and movement of sand dunes would be investigated using a variety of material and methods, including satellite imagery, remote sensing, intelligence GIS and statistical methods to find their possible threats for city and its settlers; thus the Landsat 5 Thematic Mapper (TM) acquired in Jun 1986, The Advanced Spaceborne Thermal Emission and Reflection Radiometer (ASTER) acquired in Jun 2001, Jun 2010, and Landsat 8 Operational Land Imager (OLI) and google earth remote sensing images acquired in Jun 2016, were used to identify the dunes,dunes transition and their geomorphological parameters. These images have been used to analyze the morphology and topography of the sand dunes. Wind data recorded by Iran Yazd Meteorological Information Center has been used. Wind data included daily maximum wind speed and direction (Figs. 4 and 5). The sand dune boundaries and ridges which were clearly defined in the remote sensing images were imported in remote sensing software. These temporal satellite images were used for trending dunes by a modern method such as MLP while the classical remote sensing techniques for monitoring sand dune migration are carried out comparing multi-temporal images and aerial photographs (Gad, 2016; Gad and Ali, 2011; Kamel et al., 1982; Hereher, 2000; Elbana, 2004). By using the GIS software, the continuous polygons and polylines to represent the areas and ridges of the sand dunes were extracted from the georeferenced, remote sensing images. Some ground control points (GCP) were used for monitoring and selecting the sand dunes shapes and properties and then for doing statistical analysis in statistical software (Fig. 2). Some infrastructure and the available data were considered for predicting modeling. Digital elevation model (DEM) data are acquired from the US National Aeronautics and Space Administration's ASTER Global Digital Elevation Model Version 2 (GDEM V2) with 30-m horizontal and 20-m vertical 
resolution. also other infrastructure layers that can affect the transition of dunes, such as road networks, villages, and city location, were prepared. These layers and classified land uses of the region were imported into GIS software. For predicting the dune movement, it was assumed a static condition for GIS layers in transition sub model. The artificial neural network (ANN) operation uses some layers for trend changes. In this research ANN was run with default options in GIS software (e.g. 10000 iterations, 25000 sample, 50\% for test and 50\% for training, stop at 0.01 Root Mean Square Error (RMSE)). Then decision making was made for future programs based on statistical and GIS method results. The flow chart of steps is shown in (Fig. 3).
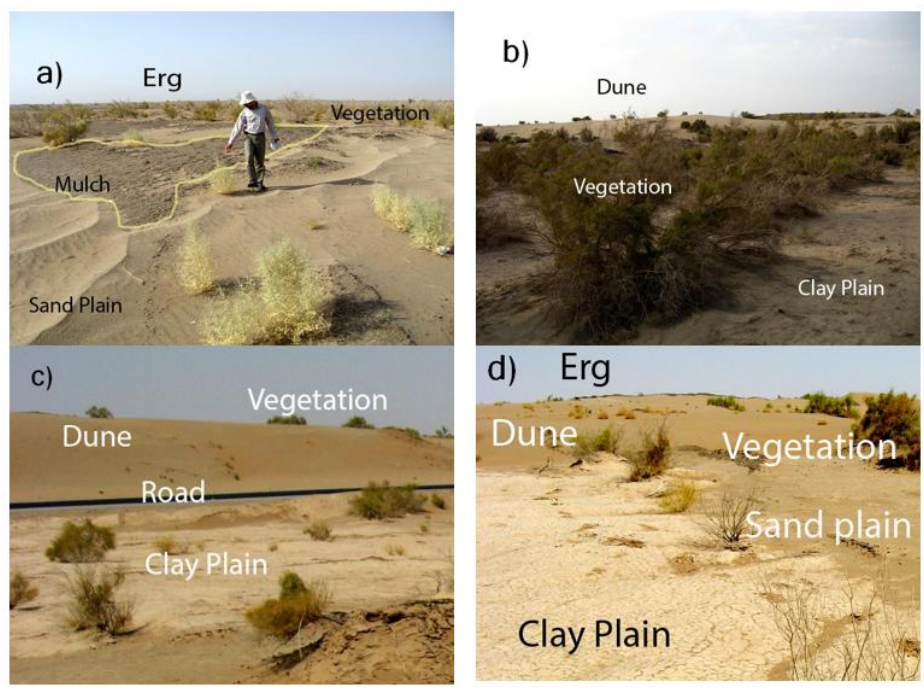

Figure 1. Photo of Erg and dunes a) some mulch in the area b) Taq vegetation c) road next to dune d) clay and sand plain

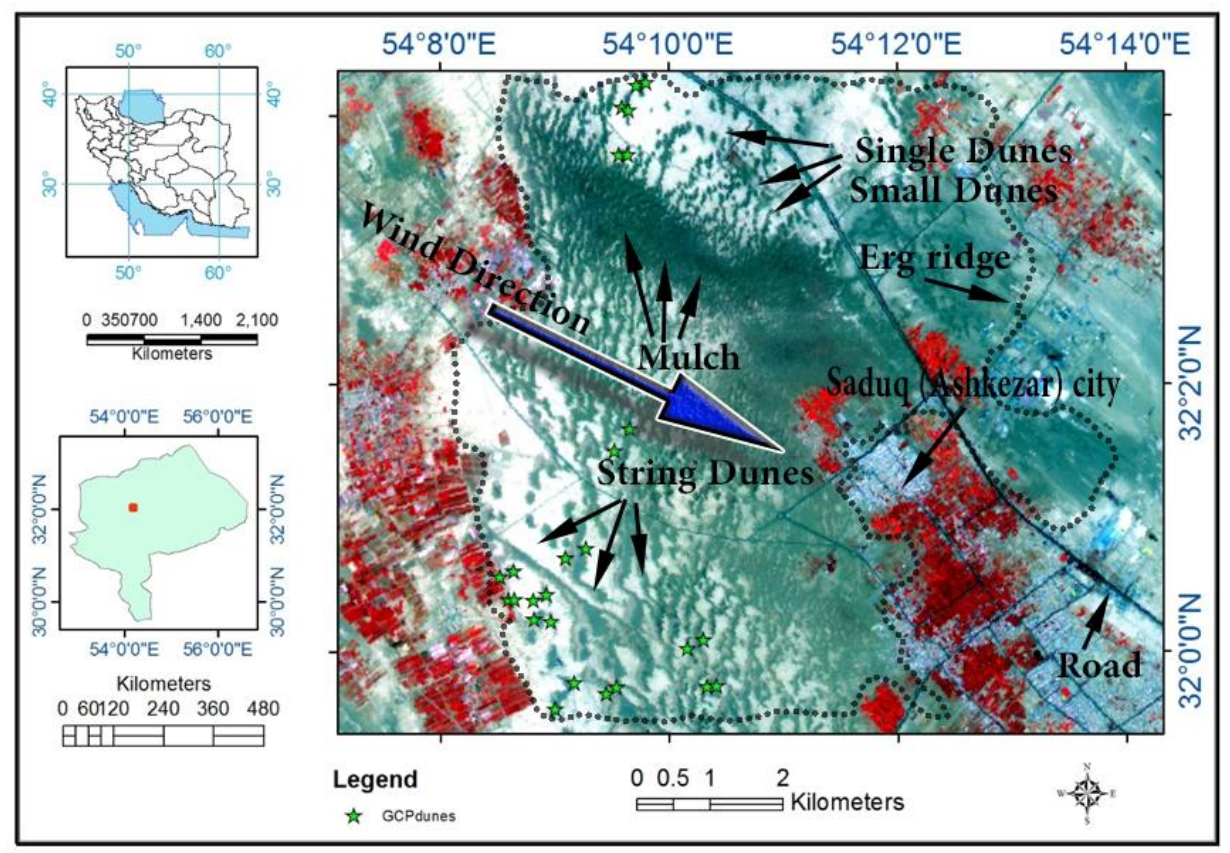

Figure 2. Location of the study areas, stars shows ground control points (GCP) on the ASTER 2010 image Red, Green, Blue (RGB) 432 


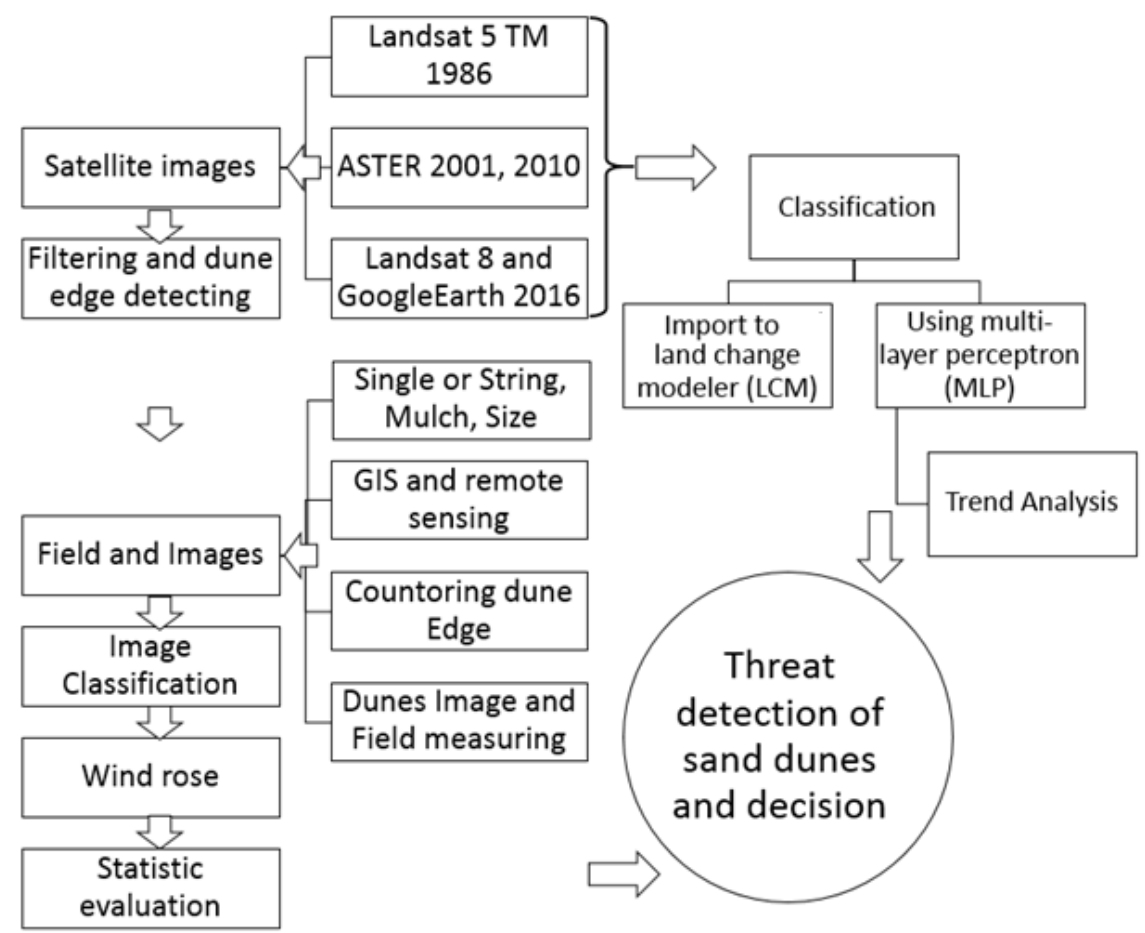

Figure 3. Flow chart of study

\section{Results and discussion}

\section{Wind and dune movement}

The statistical results show that the characteristics of dunes are greatly different in different sand formation progresses and environmental characteristics. Dunes kurtosis, collection, and movement, reflect the influence of intensive winnowing processes downwind of obstacles. Results obtained from the Wind Rose Plot (WRPLOT) software analysis indicated that the direction of prevailing winds in Yazd Erg was generally from west to northwest. Interpretation of aerial photos and satellite imagery show that sand dunes were formed along these predominant winds. These kinds of dunes have two wind sides with different slopes. The low slope side (the upwind side) shows the direction of the predominant wind. Among the anemometric data employed in the research, the frequency percentage of calm winds with a velocity of less than one knot $\left(0.54 \mathrm{~m} \mathrm{~s}^{-1}\right)$ was $0.59 \%$, and average wind speed was $6.83 \mathrm{~m} \mathrm{~s}^{-1}$. Based on the storm rose, the frequency of winds of a velocity less than $6 \mathrm{~m} \mathrm{~s}^{-1}$ (threshold velocity) is 93.79\% as observed from Yazd meteorological station, and the frequency of dust storm winds is reduced to $6 \%$. The analytical results of the grain size in Erg sand dunes show that the mean grain sizes vary between 180 and $300 \mu \mathrm{m}$ (about $280 \mu \mathrm{m})$, and the values of sorting and Skewness are 1.4 and -0.17 , respectively (Mesbahzadeh and Ahmadi, 2012). Figures 4 and 5 shows that the dominant wind has come from the northwest, thus the dunes were expected to move toward southeast.

\section{Movement}

The dunes were selected from the satellite images for the statistical survey during 1986 to 2016 (30 years). A comparison was made for size in two groups, small and big 
dunes. These samples were independence, and nonparametric test Man-Whitney U test was used for this comparison. Figure 5 shows more movement in small dams, so that about 12 dunes had about 50m movement or drift. The result shows more movement in small dunes. The other comparison was conducted about the presence of mulch on the dunes (Figure 5). The dunes with mulch and without mulch have $38.3 \mathrm{~m}$ and had 42.7 $\mathrm{m}$ movement, respectively. We understood the dunes with mulch are more stable. The mulch is the fuel that is used around 1980 in the region and its protective effect is acceptable.

In another set of dunes comparison was statistically dunes and single-threaded. The two groups were significantly different from the dunes. During the time that the satellite images were compared to string and collected dunes have more than a single movement (Figure 5).

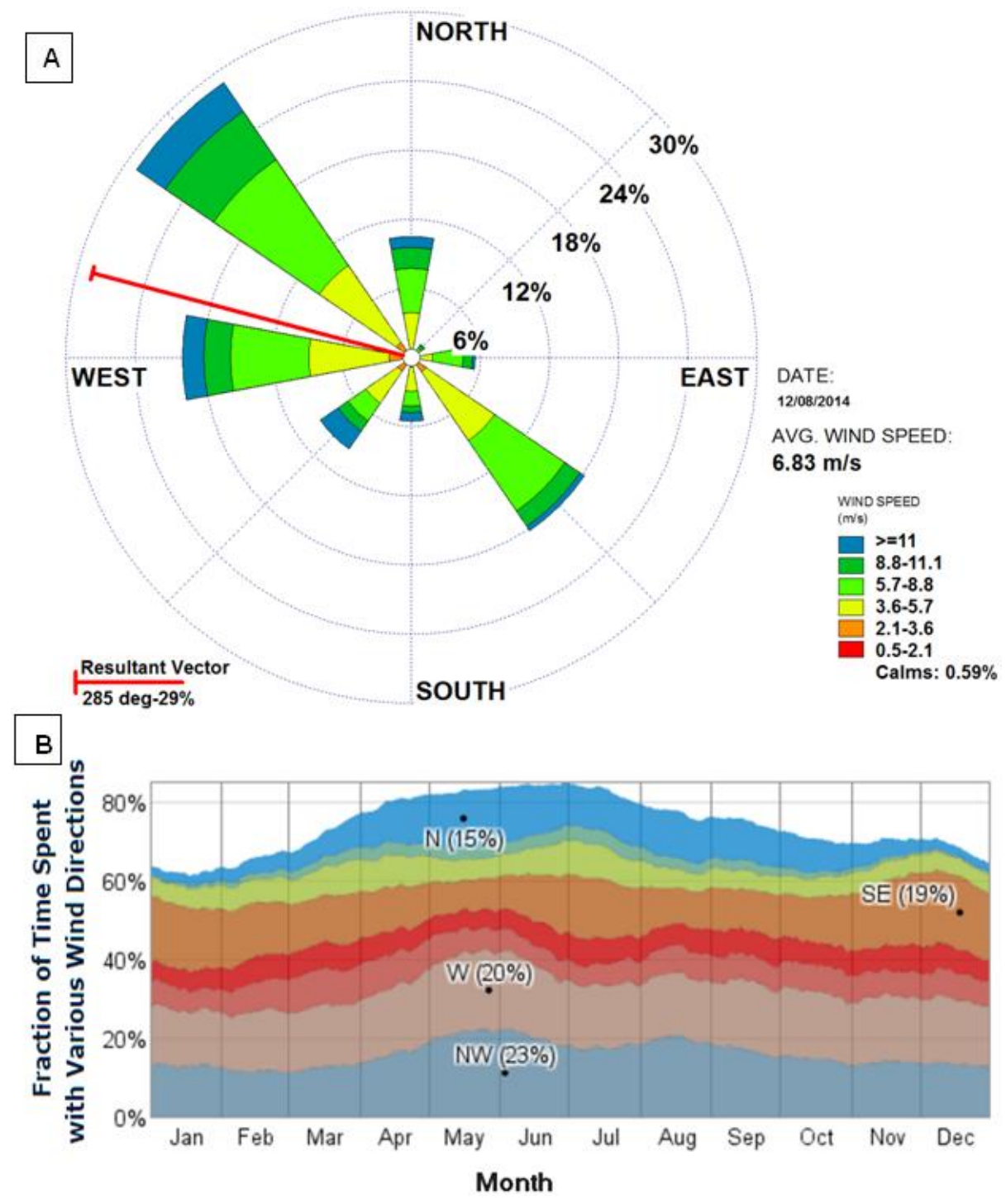

Figure 4. A: Ten years Annual WRPLOT of Yazd region (2004 to 2014). B: The fraction of time spent with the wind blowing from the various directions on a daily basis. Stacked values do not always sum to $100 \%$ because the wind direction is undefined when the wind speed is zero (2006 to 2012) (https://weatherspark.com/averages/32839/Yazd-Ir) 12/0/2016 

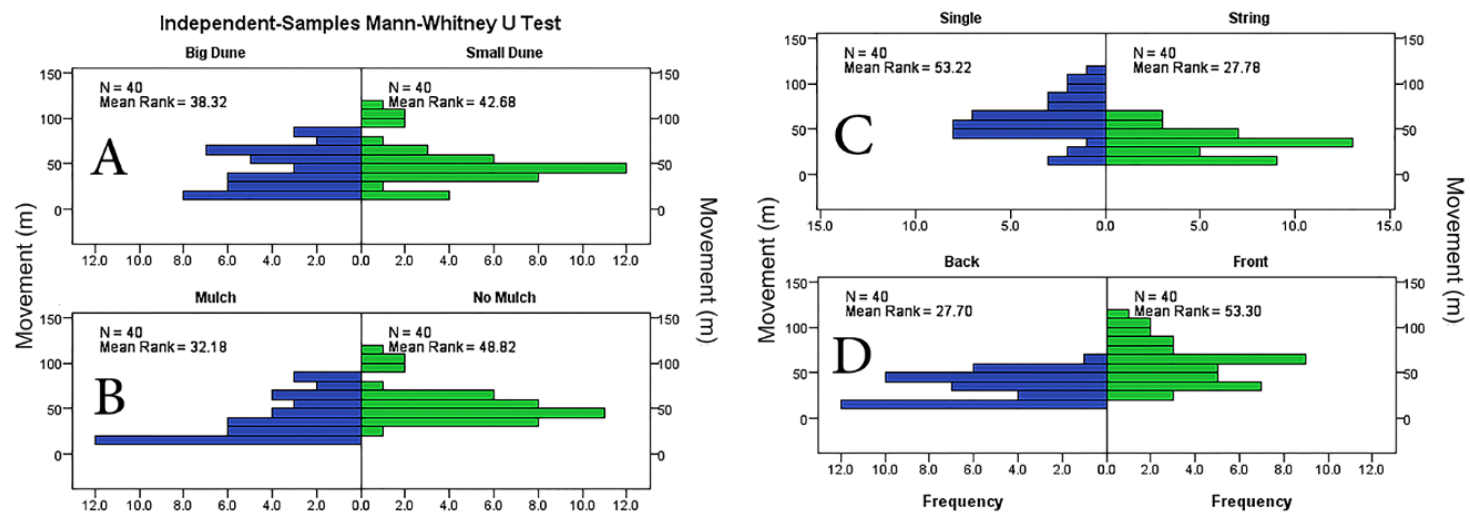

Figure 5. Comparing displacement (movement) A) big and small dunes, B) Using mulch and no mulch, $C$ ) single and string dunes, D) Dune's stoss (front) and lee (back) side relative to wind direction

\section{Movement and vulnerability trends}

Sand dunes were sampled using satellite imagery and field surveying. Figure 6 shows four regions which were selected for measuring and monitoring sand dune movement base on their geomorphic properties.

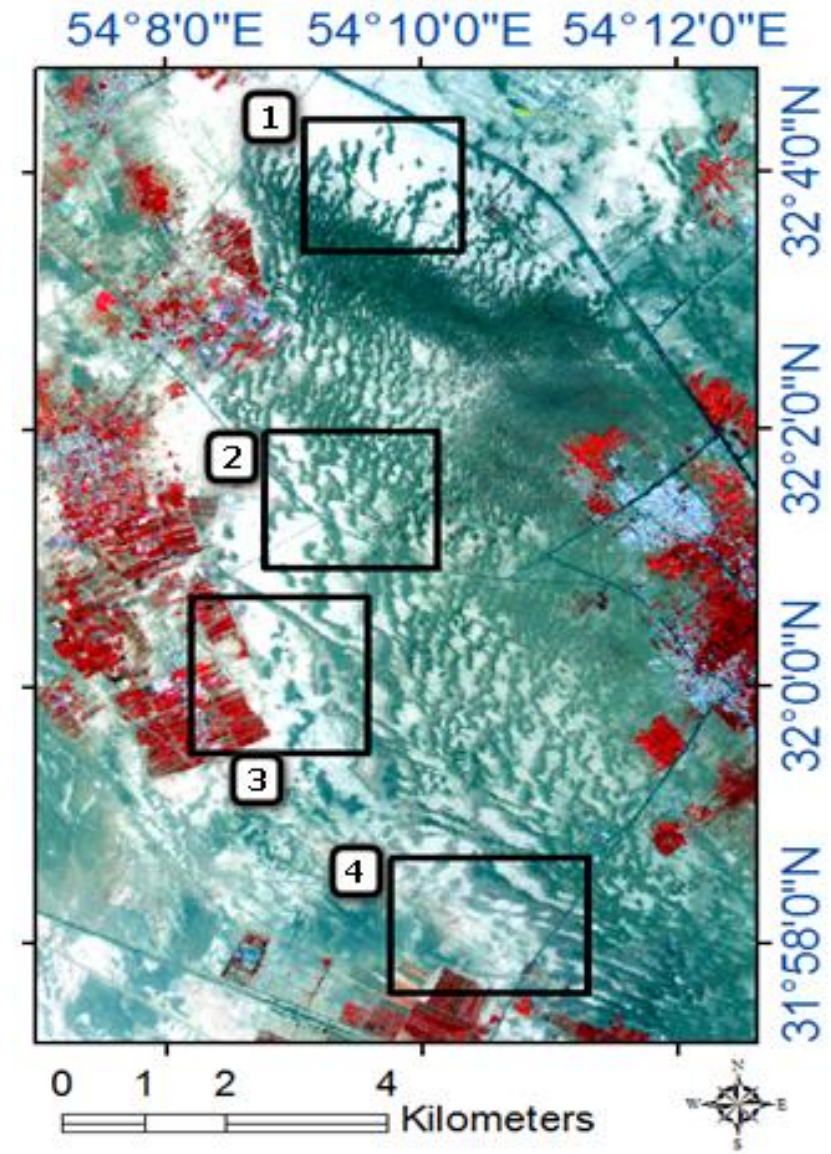

Figure 6. Sand dunes sampling 1 to 4 for Figure 7 
Figure 7 shows Sand dunes movement measuring and making comparison by size using GCP and satellite images, row2 comparison by Mulch row3 comparison by shape (single and string) row4 comparison by shape (stoss (front) and lee (back) sides; Fig. 7).
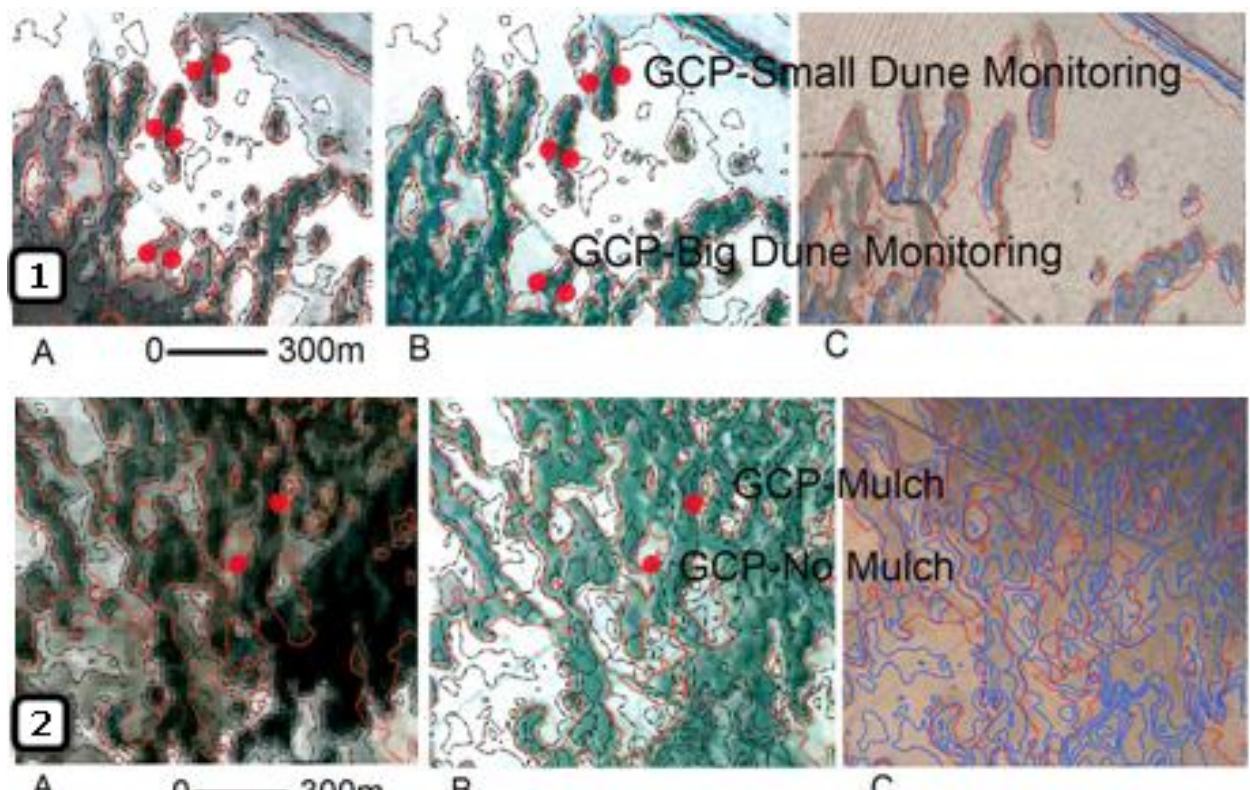

A

$0 \longrightarrow 300 \mathrm{~m}$

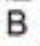

C
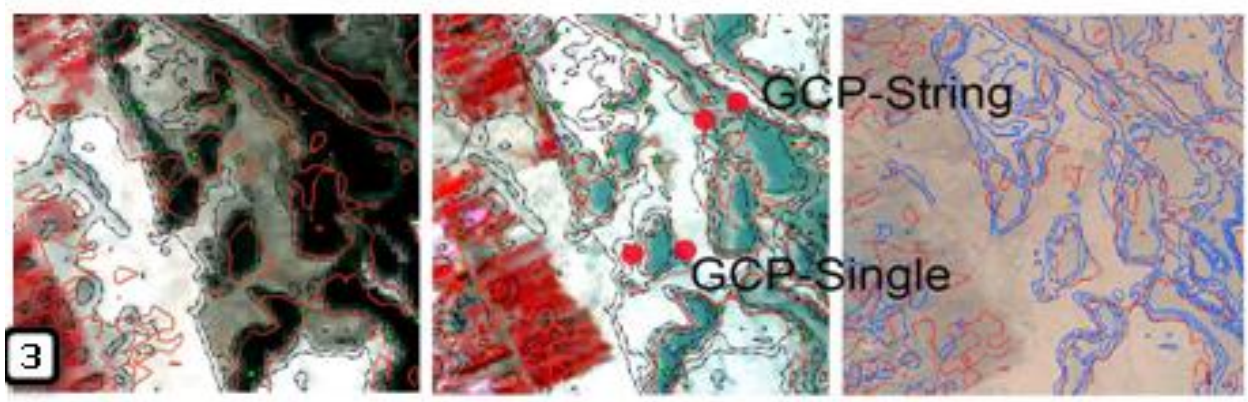

A

$300 \mathrm{~m}$

B

C

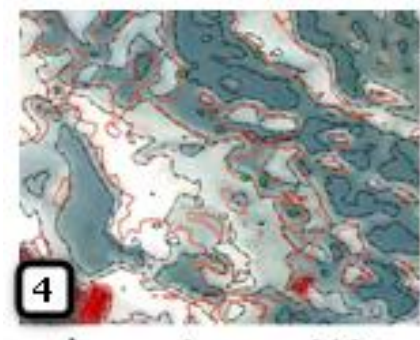

A

$300 \mathrm{~m}$

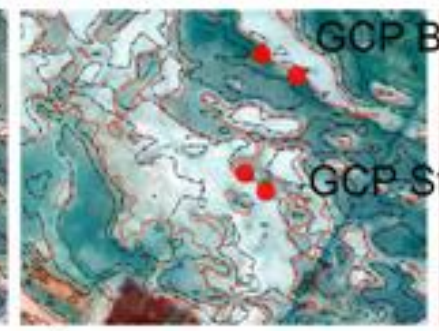

B

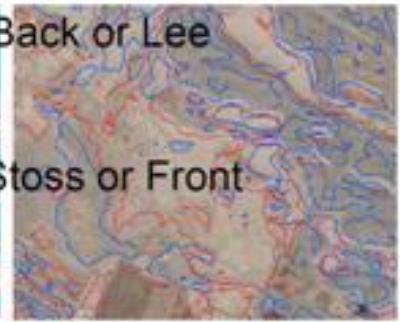

C

Figure 7. Row1: Sand dunes movement measuring by size from GCP (ground control point) and image: big and small sand dunes, left to right TM1986, ASTER2010 and Google Earth (GE) (lines shows recent border and edge of dunes in past), Row2:Sand dunes movement measuring by Mulch from GCP and image: Mulch and no mulch on sand dunes, left to right TM1986, ASTER2010 and GE, Row3: Sand dunes movement measuring by shape from GCP and image: Single and String sand dunes, left to right TM1986, ASTER2010 and GE, Row4: Sand dunes movement measuring by shape from GCP and image: Dune's stoss (front) and lee (back) sides, left to right TM1986, ASTER2010 and GE 
The dune transition and trends could be achievable by using GIS software and MLP neural network. MLP neural network analysis results in preparing four maps of dune trends: A: Potential for the transition from dune to vegetation (west of the region has more potential); B: Potential for the transition from dune to sand plain (west of the region has more potential); C: Potential for the transition from sand plain to vegetation (west of the region has more potential); D: Potential for transition from sand plain to clay plain (east part of the region has more potential).

It can be found that dunes are stabled in this region, and residents would change land uses to vegetation. Trend and transfer were assessed for vegetation to sand dunes. The city and villages are threatened with the direction east to west, and most unsuitable changes occurred near the city and where there are intensive road networks (Fig. 8).

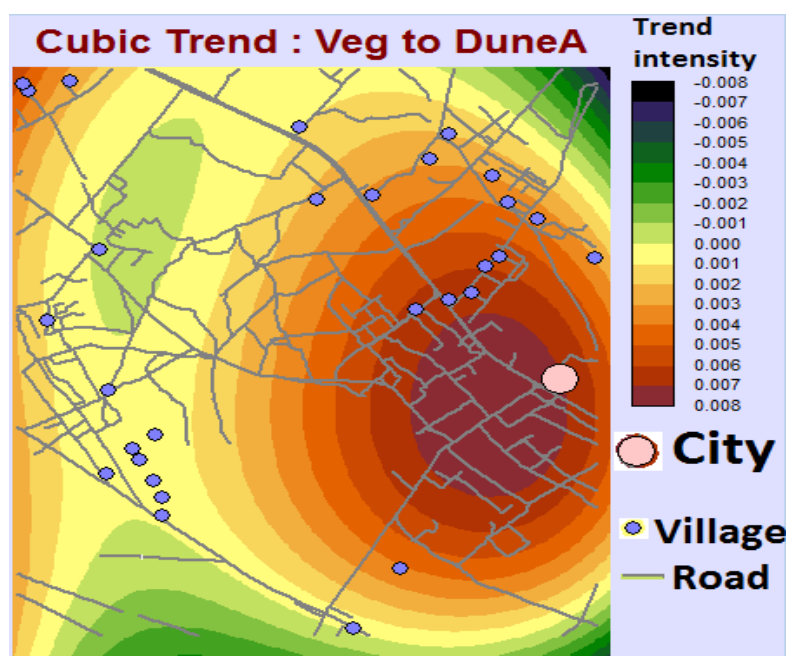

Figure 8. Trend and transfer for vegetation to sand dunes; the city and villages are threatened by this trend east to west, and more severe change is near the city and where it is road intense

The vulnerability is a weakness of an asset or group of assets that can be exploited by one or more threats (International Organization for Standardization/International Electrotechnical Commission (ISO/IEC), "Information Technology-Security TechniquesInformation security risk management" ISO/IEC FIDIS 27005:2008). In this region, road networks, agricultural and residential land uses are vulnerable, and sand dune movement is a hazard factor that should be controlled. The settlers, villagers, and government are expanding vegetation covers to reduce the vulnerability of land uses now.

In the past (about 1980) black oil mulch was used on the part of Erg near villages and cities, but today's using vegetation cover and biological controlling is the main policy of government because it is safe and healthy. Settlers were encouraged to plant more row trees perpendicular to the predominant wind by distribution sidles by Saduq (Ashkezar) and Yazd Natural Resources and Watershed Management Office.

Some settlers and other people in a 50-year period should leave their assets, lands, and homes because of the sand dunes onset toward their lands. This problem should be studied by modern methods such as remote sensing, GIS, and MLP to show the settlers and the decision makers the future of sand dune movements and their threats. In anticipation of the neural network and trend study it was found that sand dunes will migrate to the areas with denser road networks and residential (city and villages) areas. Rural and urban development and road networks, as well as the prevailing wind from the 
west to the east, could be the main reasons for this trend. Reduced groundwater levels and declining rainfall can also reduce vegetation during these recent years, and it has caused the development of the dunes. Vast areas with $30 \mathrm{~km}$ far from the Yazd Erg in the west has no vegetation cover, thus this region also can be a sand source that the wind can bring them into the Erg. This sand source is also caused growing the sand dunes and incursion them toward residential areas. Using MLP neural network, GIS, and statistical surveys could show the discussed changes and trends in the status of sand dunes by measuring in time series satellite images as well as filed measures. Mirhosseini et al. (2016), Julien et al. (2011), Emami et al. (2014), Zhang et al. (2014), Hegazy and Kaloop (2015) also confirm this trend and changes in the Erg and dunes related the variation land uses. Considering these results, municipal managers can decide better for urban development by preventing further conversion of vegetation into the dunes and moving dunes toward urban areas.

Main findings related to wind effects revealed that predominant wind direction is from northwest to southeast.

\section{Conclusion}

According to the findings, sand dunes move toward the vulnerable area in southeast and east of Erg such as Saduq (Ashkezar) city and roads. Small, single and without mulch dunes moves more than big, strong and mulch covered sand dunes.

The trend of movement base on wind direction is toward the city and land change from dune to vegetation, such that west of the region has more potential and show villager positive activity in planting. Another trend shows a transition from sand plain to vegetation so that west of the Erg region has more potential and Erg is moving from west to east following the prevailing wind direction. The dunes displacement (movement) was dependence to size big or small, cover mulch or without mulch and shape and direction of them. These analyses can help to city governor and mayor for preventing of dunes offense toward the city. Today's primary policy is using vegetation cover and biological controlling by the government. Settlers were encouraged to plant more row trees perpendicular prevailing wind by distributing seedlings by population centers.

Future extensions of this research for future researches: It is proposed such as using other spatial factors for logistic regression to find effective factors on Erg expansion and sand dune movement. The relation between groundwater, rainfall, and Erg changes can be studied. Installing of some wind break and effect of the sand movement during years can be considered.

Acknowledgements. This research was funded by the research and technology deputy, Maybod BranchIslamic Azad University (Interior Project). The authors thank the help of all the experts who have aided in this project.

\section{REFERENCES}

[1] Al-Masrahy, M. A., Mountney, N. P. (2013): Remote sensing of spatial variability in aeolian dune and interdune morphology in the Rub' Al-Khali, Saudi Arabia. - Aeolian Research 11: 155-170.

[2] Baas, A. C. (2007): Complex systems in aeolian geomorphology. - Geomorphology 91: 311-331. 
[3] Baghestani, N., Zandi Esfahan, E., Zare, M. T. (2015): Effects of pruning on Haloxylon Aphyllum L. dimensions and its application in biological reclamation of desert regions in Yazd Province. - Journal of Range Science 5: 153-161.

[4] Breed, C. S., Grow, T., Chapter, J. (1979): Morphology and Distribution of Dunes in Sand Seas Observed by Remote Sensing. - In: Mckee, E. D. (ed.) A Study of Global Sand Seas. US Geological Survey, Washington.

[5] Bullard, J. E., White, K., Livingstone, I., (2011): Morphometric analysis of aeolian bedforms in the Namib Sand Sea using ASTER data. - Earth Surf. Proc. Land. 36: 15341549 .

[6] Cooke, R. U., Warren, A. (1973): Geomorphology in Deserts. - University of California Press, Berkeley.

[7] Elbanna, M. S., (2004): Geological Studies Emphasizing the Morphology and Dynamics of Sand Dunes and Their Environmental Impacts on the Reclamation and Developmental Areas in Northwest Sinai, Egypt. - PhD Dissertation, Department of Geology, Cairo University, Egypt.

[8] Elbelrhiti, H. (2012): Initiation and early development of barchan dunes: A case study of the Moroccan Atlantic Sahara desert. - Geomorphology 138(1): 181-188.

[9] Elbelrhiti, H., Claudin, P., Andreotti, B. (2005): Field evidence for surface-wave-induced instability of sand dunes. - Nature 437(7059): 720-723.

[10] Emami, J., Jamali, A. A., Morovvati, A., Shamsi, H. (2014): Comparison abandoned dryland, dryland and rangeland land uses in arid region Yazd-Iran. - Indian Journal of Fundamental and Applied Life Sciences 4: 1124-1131.

[11] Evans, J. R. (1962): Falling and climbing sand dunes in the Cronese ("Cat") Mountain area, San Bernardino County, California. - The Journal of Geology 70(1): 107-113.

[12] Gad, A. (2016): Sand dune distribution and related impacts on agricultural resources of Sinai Peninsula, Egypt, using integrated remote sensing-GIS techniques. - Global Advanced Research Journal of Agricultural Science 5(1): 042-050.

[13] Gad., A., Ali, R. (2011): Creation of GIS digital land resources database of the Nile Delta, Egypt, for optimal soil management. - Procedia Social and Behavioral Sciences 19: 641-650.

[14] Ghadiry, M., Shalaby, A., Koch, B. (2012): A new GIS-based model for automated extraction of sand dune encroachment case study: Dakhla Oases, Western Desert of Egypt. - The Egyptian Journal of Remote Sensing and Space Science 15: 53-65.

[15] Hegazy, I. R., Kaloop, M. R. (2015): Monitoring urban growth and land use change detection with GIS and remote sensing techniques in Daqahlia Governorate Egypt. International Journal of Sustainable Built Environment 4: 117-124.

[16] Hereher, M. (2000): A Study on Sand Dunes Fields in North Sinai and the Environmental Risk Assessment of Aeolian Processes. - MSc Thesis, Faculty of Science (Dumyat), Mansoura University, Egypt.

[17] Hugenholtz, C. H., Barchyn, T. E. (2010): Spatial analysis of sand dunes with a new global topographic dataset: new approaches and opportunities. - Earth Surface Processes and Landforms 35(8): 986-992.

[18] Jamali, A. A., Abdolkhani, A. (2009): Preparedness Against Landslide Disasters with Mapping of Landslide Potential by GIS-SMCE (Yazd-Iran). - International journal of geoinformatics 5(4): 25-31.

[19] Julien, Y., Sobrino, J. A., Jiménez-Muñoz, J. C. (2011): Land use classification from multitemporal Landsat imagery using the Yearly Land Cover Dynamics (YLCD) method. - International Journal of Applied Earth Observation and Geoinformation 13: 711-720.

[20] Kamel, A., Elrakaiby, M. M., Elkassas, L. A. (1982): Photo interpretation of sand dune belts in northwestern Sinai - Egyptian Journal of Geology 1982(Special Issue, Part 1): 57-70.

[21] Kocurek, G., Ewing, R. C. (2005): Aeolian dune field self-organization - implications for the formation of simple versus complex dune-field patterns. - Geomorphology 72(1): 94-105. 
[22] Kocurek, G., Ewing, R. C., Mohrig, D. (2010): How do bedform patterns arise? New views on the role of bedform interactions within a set of boundary conditions. - Earth Surf. Landforms 35: 51-63.

[23] Kocurek, G., Lancaster, N. (1999): Aeolian system sediment state: theory and Mojave Desert Kelso dune field example. - Sedimentology 46: 505-515. DOI: 10.1046/J.13653091.1999.00227.X.

[24] Lancaster, N. (1995): Geomorphology of Desert Dunes. - Routledge, London.

[25] Li, Z. S., Ni, J. R. (2000): A review of desert dune geomorphology. - Journal of Sediment Research 5: 73-81.

[26] Livingstone, I., Wiggs, G. F. S, Weaver, C. M. (2007): Geomorphology of desert sand dunes: a review of recent progress. - Earth-Science Reviews 80: 239-257.

[27] McCulloch, W. S., Pitts, W. (1943): A logical calculus of the ideas immanent in nervous activity. - The Bulletin of Mathematical Biophysics 5(4): 115-133.

[28] Mesbahzadeh, T., Ahmadi, H. (2012): Investigation of sand drift potential (case study: Yazd-Ardakan Plain). - J. Agr. Sci. Tech. 14: 919-928.

[29] Meyer, T., Crews Meyer, K. A. (2016): Integrating Multiplatform Remote Sensing and in Situ Datasets for Socio-Ecologically Sustainable Conservation Corridors: The Western Kalahari Conservation Corridor (WKCC) Project. - In: Scott, A. E. et al. (eds.) Reference Module in Earth Systems and Environmental Sciences. Elsevier, Amsterdam.

[30] Mili, S. (2016): Instant cities on the wet coastal zones - Tunisia. - Procedia Environmental Sciences 34: 525-538.

[31] Mirhosseini, S. M., Jamali, A. A., Hosseini, S. Z. (2016): Investigating and Predicting the Extension of Dunes Using Land Change Modeler (LCM) in the North West of Yazd, Iran. - Desert 21(1): 76-90.

[32] Potter, C. (2016): Analysis of desert sand dune migration patterns from Landsat image time series for the Southern California Desert. - Journal of Remote Sensing \& GIS 5: 1-8.

[33] Pye, K., Tsoar, H. (1990): Aeolian Sand and Sand Dunes. - Unwin Hyman, London.

[34] Saqqa, W., Atallah, M. (2004): Characterization of the aeolian terrain facies in Wadi Araba Desert, southwestern Jordan. - Geomorphology 62(1) 63-87.

[35] Sweet, M. L., Nielson, J., Havholm, K., Farrelly, J. (1988): Algodones dunefield of SE California: case history of a migrating modern dune field. - Sedimentology 35: 939-952.

[36] Tang, Z., Lindell, M. K., Prater, C., Wei, T., Hussey, C. M. (2011): Examining local coastal zone management capacity in US Pacific coastal counties. - Coastal Management 39(2): 105-132.

[37] Tavakkolifard, A., Ghasemieh, H., Nazari Samani, A. A., Mashhadi, N. (2013): Determining the risk of sand transportation to residential areas around Kashan Erg using anemometry data analysis. - Desert 18: 163-172.

[38] Tsoar, H. (1983): Wind tunnel modeling of echo and climbing dunes. - Elsevier, Amsterdam..

[39] Tsoar, H., Blumberg, D. A. N. (2002): Formation of parabolic dunes from barchan and transverse dunes along Israel's Mediterranean coast. - Earth Surface Processes and Landforms 27(11): 1147-1161.

[40] Wilkins, D. E., Ford, R. L. (2007): Nearest neighbor methods applied to dune field organization: the Coral Pink Sand Dunes, Kane County, Utah, USA. - Geomorphology 83(1): 48-57.

[41] Wu, Z. (2003): Aeolian Landform and Sand Control Engineering. Beijing: Science Press, p. 261-266.

[42] Xiao, J. H., Qu, J. J., Yao, Z. Y., Pang, Y. J., Zhang, K. C. (2015): Morphology and formation mechanism of sand shadow dunes on the Qinghai-Tibet Plateau. - Journal of Arid Land 7: 10-26.

[43] Zhang, S., Liu, Y., Wang, T. (2014): How land use change contributes to reducing soil erosion in the Jialing River Basin, China. - Agricultural Water Management 133: 65-73. 